\title{
Research Leadership Development Initiative: An Experiment for a Research Career Choice
}

\section{Dr. Sara Wadia-Fascetti, Northeastern University Jan Rinehart, Northeastern University}

Jan Rinehart is Executive Director of the NSF Northeastern ADVANCE Program (HRD-0811170). She has over twenty years in higher education with most of her work focused on diversity in STEM fields. She previously served as Executive Director of the Rice University ADVANCE and Director of Engineering Student Programs at Texas A\&M University. While at Texas A\&M she was co-PI on NSF RET, SSTEM, STEP grants, and senior personnel on the NSF Coalition and LSAMP grant. She sits on several ADVANCE External Advisory Boards. Northeastern ADVANCE has resulted in an increase of female faculty from $73(21 \%)$ in 2008 to $108(26 \%)$ in 2012. In the most recent year of the grant, the program provided professional development to 294 Northeastern faculty members and 21 postdoctoral scholars and late stage Ph.D. students. Over the five years of the grant, ADVANCE hosted 248 scholars in 8 "Future Faculty Workshops"; participants were 78\% female and 13\% underrepresented minority postdoctoral scholars and Ph.D. students; four of these were interviewed at Northeastern as a result, and two were hired.

\section{Prof. Simon Pitts, Northeastern University}

Simon Pitts is the Director of Northeastern's Gordon Engineering Leadership Program and Professor of Practice in Engineering Leadership. A graduate of Loughborough University and executive education at INSEAD, Simon began his career in advanced powertrain development and research at Ford Motor Company. During his time with Ford, his assignments included leading engineering and cross functional teams as Vehicle Line Director, Director of Manufacturing Operations, and Director of Powertrain Planning and then Product Development Operations for all Ford, Jaguar, Land Rover, Mazda and Volvo brands globally. Prior to joining Northeastern, Simon served as Director of the Ford-MIT Research Alliance. 


\title{
Northeastern ADVANCE Research Leadership Development Initiative: A Program to Strengthen the Leadership Skills of Mid-Career Faculty
}

\begin{abstract}
As part of the ADVANCE program, Northeastern University launched the Research Leadership Development Initiative (ReDI) in the fall of 2012 as a leadership program for associate and early full professors. The goal is to prepare these rising research scholars to lead collaborative research teams of peers in activities to create or grow centers, institutes, and/or multiinstitutional collaborations. Through participation in the different program components, faculty participants will increase their skills in influencing team dynamics and project outcomes by learning how to manage and leverage differences. This paper describes how ReDI fits within Northeastern and the ADVANCE Program. ReDI goals, components, and outcomes are presented along with lessons learned from the first two ReDI cohorts.
\end{abstract}

\section{Introduction}

ADVANCE programs supported by the National Science Foundation (NSF) must identify the barriers that limit the opportunities for women to succeed in academic careers. By leveraging all opportunities (existing and newly created), ADVANCE programs seek to increase the numbers of women faculty. ADVANCE Institutional Transformation sites, of which Northeastern is one, must implement an organizational change model that transforms the institution into an environment that promotes the success of women faculty. Since 2001, when NSF first began funding ADVANCE sites, institutions have demonstrated that programs designed to improve the environment for a minority group, improve the environment for all. Therefore, Northeastern implements its ADVANCE program such that barriers to women are identified and reduced, while promoting the success of all faculty members. To successfully achieve organizational change, the goals related to women must be aligned with the strategic goals of the institution.

The diversification of faculty in all respects is a component of Northeastern's Academic Plan. In addition, Northeastern seeks to expand its capacity to pursue interdisciplinary transformational scholarship in research areas that are use inspired. To achieve this, it is important to prepare a new generation of faculty who are well-equipped to lead major interdisciplinary initiatives. These faculty need to have sharpened skills to lead colleagues who come from very different groups. These differences include disciplinary, gender, race and cultural background. The Research Development Leadership Initiative (ReDI) presented here is a program designed to prepare faculty for these larger research endeavors while also leveling the differences between men and women in the institution.

Within the last three years, Northeastern has launched a number of leadership development programs for both faculty and staff. Therefore, the ADVANCE ReDI program is designed to fit within this suite of development activities at the institution. The suite of programs includes: 
- Leadership Academy (four 2 hour meetings, with a project): developed and led by the Provost's Office, this initiative focuses on administrators new to the university and faculty new in administrative roles (department chair, associate dean).

- Leadership Development Program (six 1 day meetings, with a project and executive coaching): led by the President's Office and Human Resource Management, this program is offered to nominated faculty in administrative positions and senior staff who have been in leadership roles for $5-6$ years and are positioned to be upwardly mobile. The audience includes department chairs, associate deans, and administrative leaders at the associate vice provost and director level.

- Leadership Modules (four to six a year, 2 hour sessions): led by Human Resources Management, these modules are offered to professional staff in mid-level administrative positions and academic leaders such as department chairs and/or associate deans. Topics are in competence areas identified to be critical to Northeastern's success, including communications (up, down, across) and professional development (self \& others).

Through an assessment of the institutional landscape, review of existing programs, and identification of needs for women faculty, Northeastern recognized a gap for women's participation in positions that lead major research initiatives such as research centers. As a result, the ADVANCE program, in partnership with the Senior Vice Provost for Research and Graduate Education and the Gordon Engineering Leadership Program, developed the Research Leadership Development Initiative, short titled ReDI. The goal of ReDI is to increase, within the context of diversity, the leadership skills of associate professors and early full professors. This will be achieved by working with a cohort of faculty, with at least $50 \%$ women, in a series of workshops designed to provide tools to enable faculty to increase their own self-awareness and their ability to adapt to new and diverse situations.

\section{The National Setting with Women in Academic Leadership Positions}

Despite increases in the number of women faculty, women are not represented in the ranks of research center directors in the same proportion that they are full professors, which is consistent with the research on leadership programs for women. ${ }^{1,2,3,4}$ There are six over-arching dimensions for consideration in developing leadership programs for women: 1) the recognition of the challenges for women, both inside the person and also within the organization, that prevent them from advancing into senior leadership positions; 2) the need for leadership programs to address the institutional barriers as opposed to general leadership skills only; 3 ) the recognition of the effectiveness of women only leadership development programs; 4) the benefits of establishing internal and external networks for women; 5) the need to constantly reinvent the program to keep it current with institutional goals; and 6) the need for a strong encompassing evaluation program. ${ }^{4}$

In support of the six over-arching dimensions for leadership programs for women, there are also second generation institutional barriers to women reaching leadership roles such as invisible cultural beliefs, workplace structures, practices, and institutional interactions. ${ }^{5,6,7,8,9}$ These institutional barriers are gendered and promote practices that equate leadership with behaviors 
more commonly associated with men than women. Thus creating an institutional barrier for women, who appear to be ill-suited for leadership roles and are therefore not selected as leaders. Another institutional barrier is men sponsoring and advocating for men. When a leadership role becomes available, women are not sponsored for the position. ${ }^{10} \mathrm{~A}$ third institutional barrier that comes into play for women is their self-perception as a leader, or leadership self-identity. This self-identity comes from learning to lead by leading an activity, gaining positive/negative feedback, leading another activity, and gaining more feedback. This iterative process develops the ability to internalize the self-perception of being a leader. The feedback gained and the iterative process is what leads to the development of a leadership identity. If this identity is not developed, as often times it is not for women due to the institutional barriers mentioned above, when a leadership position becomes available, there are not women who see themselves as leaders ready to step up. ${ }^{5}$ To overcome these institutional barriers, leadership programs for women should include: 1) using a 360-degree feedback and coaching exercise; 2) building leadership networks both more broadly and deeply; 3) teaching a broader negotiation framework; and 4) using case studies to teach women leading change strategies and to help them identify and recognize themselves as leaders. ${ }^{5}$

It would be deceptive to not recognize that women are leading but are more likely to be in STEM disciplinary leadership than in STEM administrative or STEM scientific leadership. Disciplinary leadership is defined as "individuals who have positions in professional science associations and regulatory organizations.” Administrative leadership is defined as "leaders in universities including deans, department heads and chairs, provosts and other formal university administrative positions." Scientific leadership is defined as "individuals with formal positions (e.g. directors) at university labs and research centers or institutes. More than any of the three academic leadership positions, scientific leaders "most directly influence the production of scientific knowledge.” Scientific productivity and recognition is most strongly linked to disciplinary and scientific leadership while only grant productivity is closely linked to administrative leadership. Therefore, it is important to develop women as leaders, not only as disciplinary leaders, but also administrative and scientific leaders, by addressing any institutional barriers that may impede their career advancement. ${ }^{11}$

A 2012 evaluation report from the NSF Industry/University Cooperative Research Center (I/UCRC) examined the impact on faculty who served as I/UCRC directors. This report examined the center directors' experiences that illuminated the shift from being a single faculty researcher to a center director. They found that faculty had to develop a new set of competencies including:

1) marketing

2) negotiations and contracts

3) leading diverse teams

4) budget management and

5) selling.

These center directors reported the greatest impact for them personally was increased job satisfaction which came from having the experiences listed below:

- managing diverse teams

- developing broad research strategies

- securing financial support for new ventures 
- making significant changes to their professional networks

- increasing their interactions with U.S. industry, university administrators, and faculty researchers outside their home department or university

- increasing empowerment to affect the careers and outcomes of others involved in the center

- increasing ability to connect multiple organizations

- increasing the image of their university

- addressing important industrial and societal needs

The faculty directors reported a high level of intrinsic satisfaction, and at the same time, the faculty directors did not reduce their publications but did increase the number of collaborative papers written. These directors also highlighted the need for succession planning. ${ }^{12}$ Getting women involved as center directors is an important institutional endeavor as it develops administrative and scientific leaders from those existing disciplinary leaders.

The ADVANCE ReDI program is designed to incorporate best practices in leadership development to address the specific needs for women, aligned with institutional needs and processes. The remainder of this paper describes the first two iterations of the ReDI program, the initial development process, the program evaluation, and the redesign process.

\section{Research Leadership Development Initiative}

ADVANCE, the Senior Vice Provost for Research and Graduate Education, and the Gordon Engineering Leadership Program in the College of Engineering collaborated to design ReDI. These three groups drew equally on needed research, expertise, and skills sets. ADVANCE brought the gender lens and analysis of the barriers for women. The Senior Vice Provost for Research and Graduate Education brought the broader and long-term institutional perspective. The Gordon Engineering Leadership Program brought expertise in teaching leadership.

The objective of ReDI is to strengthen the base of future leaders for large research groups and research centers, particularly large multi institutional centers. The ReDI leadership program was developed using leadership theory and descriptions of first-hand experience gathered through conversations with experienced center directors, research leaders, department chairs, and deans. Curriculum was adapted from the Gordon Engineering Leadership program and specific models from experts in leadership theory, negotiation, and communication. A focus group comprised of associate deans of faculty affairs and potential participants was held to gain an understanding of participant reactions and their potential engagement. These conversely revealed common characteristics or skills required for successful research leaders, independent of the discipline or field, the ability to:

- Value, identify, develop, and sustain partnerships with other organizations including academic, industrial, or not-for-profit

- Develop a common vision across groups and communicate it effectively

- Recognize the need for mentorship, team building, and team dynamics

Based on these characteristics, the identified goals for ReDI are to: 
- Create a cohort of faculty, with a strong representation of women faculty, prepared to take on significant research leadership roles

- Provide development activities that help participants recognize the importance of leadership and associated management skills within their own growing research groups and collaborations

- Provide an opportunity to acquire and exercise key leadership and management skills

The ReDI design team is composed of the ADVANCE PI, Director of the Gordon Engineering Leadership Program, an engineering leadership faculty member, and the ADVANCE Executive Director. To ensure that ReDI would be viewed as a desirable program, the selection process was led by the Senior Vice Provost for Research and Graduate Education. Each college dean was asked to nominate 2 faculty members. These faculty members had already demonstrated success as individual research leaders and held the most promise for future leadership at Northeastern. The nomination process resulted in 14 faculty participants from 5 colleges with 7 women and 7 men participating.

\section{ReDI Cohort I}

Logistics for ReDI Cohort I (2012-13) were designed to be respectful of faculty time, with 2 hour lunch time meetings every other week during the fall 2012 term, for a total of eight workshops. The workshop content was based on the skills identified through conversations with existing directors and chairs. These identified characteristics were examined and further broken down into skills and then divided into the eight 2 hour workshops. Each skill-building workshop had two leaders: the subject matter expert and the faculty guest. The subject matter experts ranged from university faculty members who research/teach the subject, faculty of the practice, professional staff, and faculty researchers who were identified as "doing” a skill well. At each workshop there was also an invited faculty "guest” who provided faculty application and contextual perspective. Topics included: Foundations of Leadership, Self-Assessment, Communication Strategies, Launching \& Running Large Projects, Team Building, Conflict Management, Contracts \& Budgeting, and Negotiation. The schedule for this first offering of ReDI is included in Appendix I.

\section{Evaluation of ReDI: First Generation}

After each 2 hour workshop, the participants were sent a link to an online survey. This formative evaluation method provided the ReDI design team and presenters immediate feedback on the workshop. About half of the 14 participants provided feedback after each workshop. On the first workshop survey, participants were asked to report their goals for ReDI and what they expected to take-away from the program.

At the end of the fall semester, a longer online survey was administered. This survey had 17 questions with a mixture of ratings and short answers. Participants were also asked about their opinion for future plans of ReDI. There were 5 sections of the survey: 1) Feedback on achieving your personal goals; 2) Feedback on ReDI workshops; 3) Overall program effectiveness; 4) Thoughts about continuing ReDI; and 5) Demographics. Eight (4 men, 2 women and 2 skipped the question) of 14 participants (57\%) completed the survey, although all 
of the eight participants did not complete every survey question. The participation was disappointingly low so we informally talked with each of the ReDI participants independently. They mostly concurred with the feedback we had already received from the online survey but told us they did not participate in the survey because they did not want to write down negative feedback.

Participants had provided their goals for the program at the beginning of the course in a presurvey. On the final online survey we asked them to what degree they found the ReDI course satisfied each of their reported goals. The participants were asked to rate each goal on a 5 point Likert scale from Did Not Satisfy (1) to Extremely Satisfied (5). (4 responses)

- Learning skills of an effective research leader (4.0)

- Learning how to manage budgets (4.0)

- Learning new communication strategies (3.5)

- Learning to inspire others (3.0)

Participants were asked to rate each workshop on a 5 point Likert scale from Not at All Valuable (1) to Extremely Valuable (5): (5 responses)

- $\quad$ Self-Assessment (MBTI was used) (3.7)

- Foundations of Leadership (3.5)

- Negotiation Skills (3.3)

- Communication Strategies (DISC was used) (3.2)

- Team Building Theory and Practice (3.0)

- Launching and Running Large Projects (2.7)

- Conflict Management Strategies (2.5)

- Contracts and Budgeting (2.2)

Participant comments were varied and consistently asked for more on the 'nuts and bolts' of center grant preparation and the skills to manage the center once awarded.

"I wanted to understand why we should bother with center grants. I have maintained 5-8 active grants at a time since I've been at Northeastern, and see value in diversification and the maintenance of a large cadre of collaborative research topics that would not necessarily be satisfied if I replaced them with a single large grant."

“The ReDI course had very ambitious goals, which I do not think were entirely met. However, I was generally satisfied with the course and learned about myself as a leader and some techniques for dealing with and motivating others that are of different personality types. Given the amount of time I spent on it, I learned quite a bit. I am enjoying reading the negotiation book and other materials." 
Participants were asked to rate how interested they were in developing a research center before and after the ReDI program. There was a slight increase in their interest from 3.5 to 3.7 (6 responses).

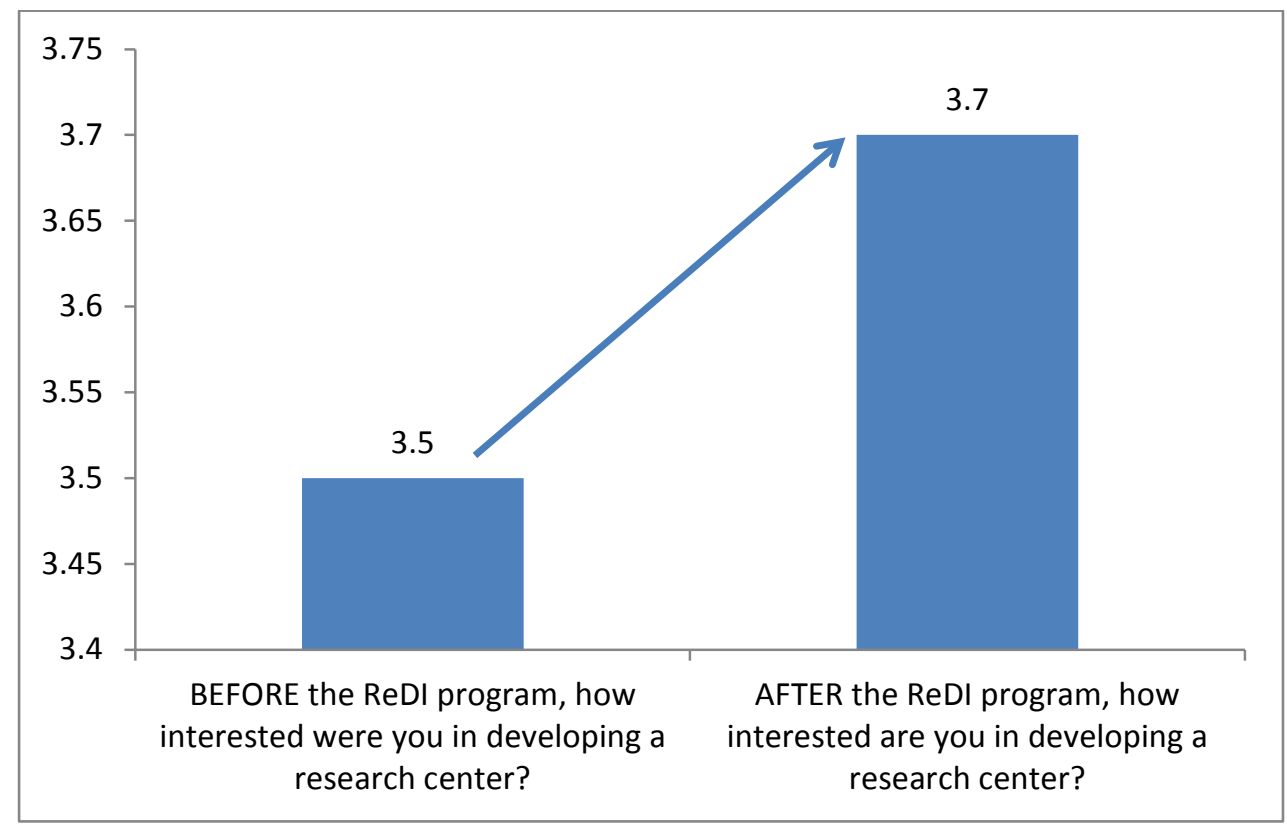

Participants were asked to rate their level of confidence in their leadership skills before and after participating in ReDI. There was a slight increase in their reported level of confidence from 3.2 to 3.3 (6 responses).

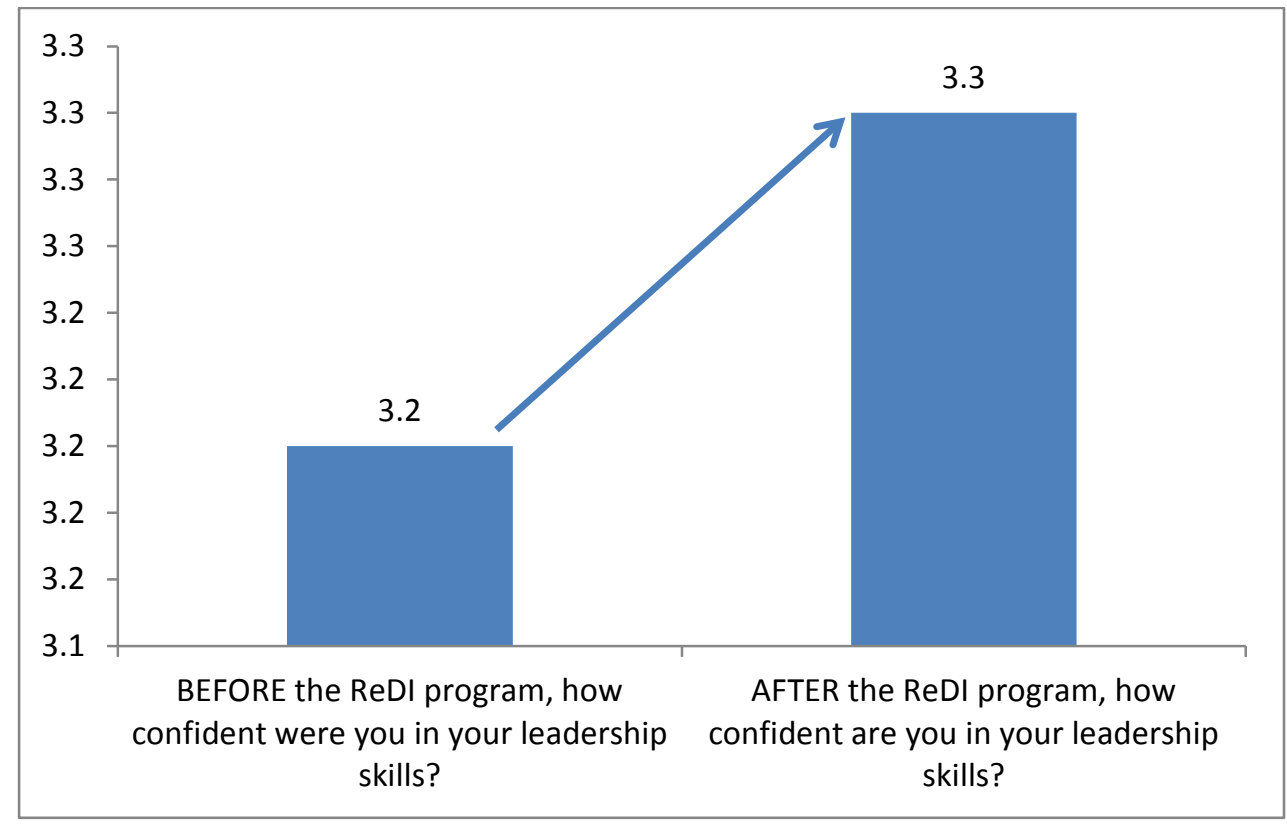


Participants were asked overall, how valuable the ReDI program was to them (6 responses).

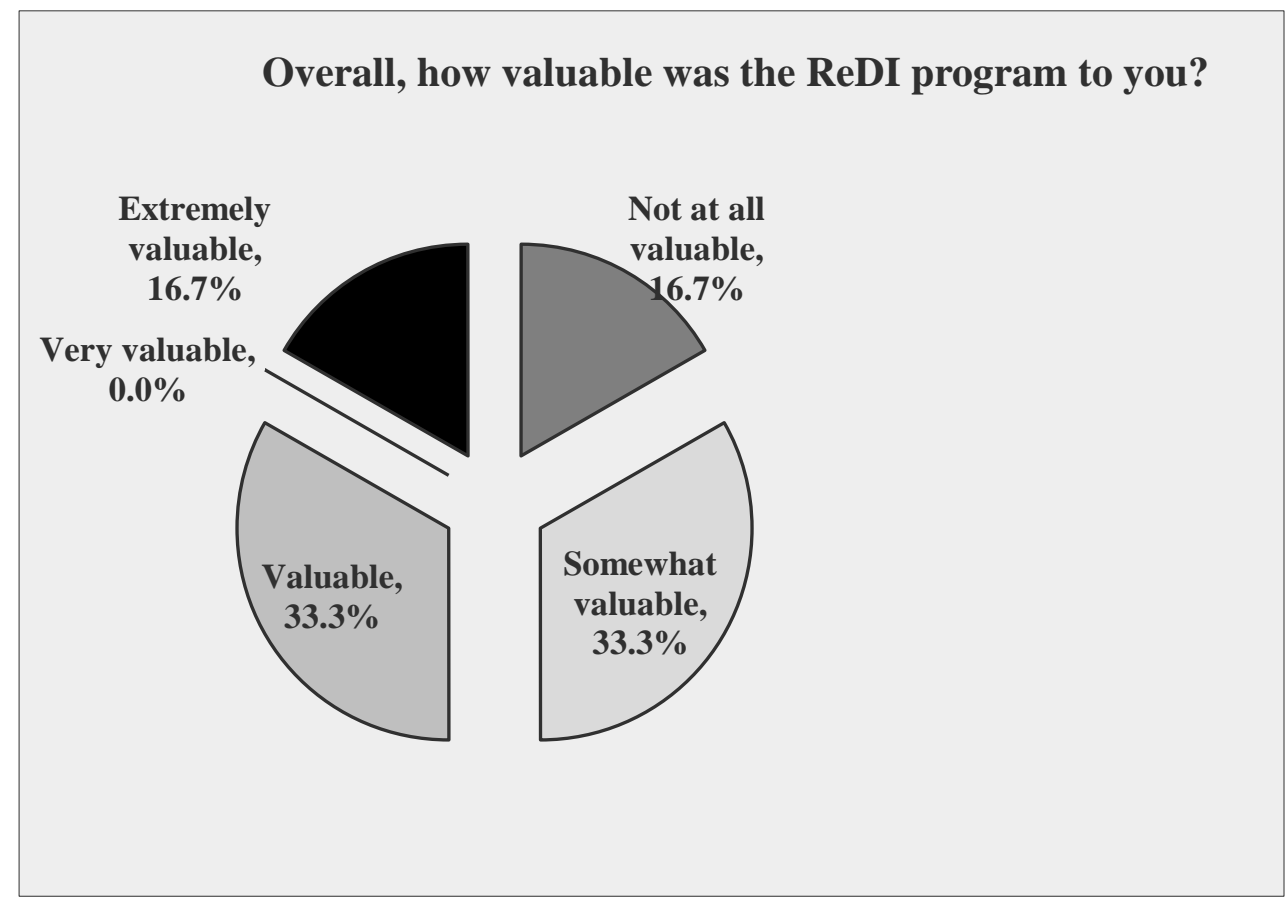

Many of the ReDI participants requested a round table to discuss the ReDI program as a group. In response to this request, ADVANCE hosted a two hour discussion in January 2013. In the course of the discussion, the faculty identified further needs and developed a plan that entailed meeting with senior administrators and center directors, forming interest teams, and then working on collaborative ideas. They wanted to learn skills "just in time" of when they need them, versus sitting through a workshop they may not know how to apply to their daily lives. They expected and wanted more interaction with each other to become a tightly knit cohort. They requested a "coach” for each interest team and feedback on their research ideas.

The first cohort was extended into the spring 2013 where the group was invited to meet with four center directors and university administrators, and encouraged to participate in the pursuit of one of Northeastern's research planning grants. Northeastern has set aside funds to promote the development of large and successful research proposals. These funds are available to teams of faculty pursuing large and complicated proposal efforts that have a specific target date. ReDI faculty members are encouraged to pursue these funds as they embark on larger projects.

The initial success of at least five ReDI participants is evidenced by their progress/movement. Since the beginning of the first cohort and to date, we know that one faculty member was asked to be associate dean for academic affairs in their college, one is leading a research center with a grant proposal submitted, one submitted a large interdisciplinary grant proposal, one is running a humanities center, and one was invited to give a TED talk at the TEDWomen conference. We will continue to track leadership milestones and grant proposals submitted by the Cohort I faculty. 
The complete evaluation summary from ReDI Cohort I is included in Appendix II. In short, ReDI Cohort I was a sequence of seminars that brought useful information to participants.

\section{ReDI Cohort II}

The second generation of ReDI was offered during the 2013 - 2014 academic year, and the revised program responds to the first generation evaluation. Specifically, Cohort II ReDI incorporates experiential components to provide faculty participants an opportunity to work together in research-oriented activities. The design team was broadened to serve three purposes: 1) to strengthen faculty participants' potential to lead larger initiatives; 2) to provide a transformational development for each faculty participant; and 3) to further connect ReDI with institutional goals. Joining the first four design team members are: Senior Vice Provost for Undergraduate Education and Experiential Learning, University Human Resources Training Manager, and an external consultant. The Senior Vice Provost of Undergraduate Education and Experiential Learning came to Northeastern in 2012-13 and has a distinguished record of faculty research and development. She also brings with her the experience and knowledge to sustain ReDI. The Human Resource Training Manager was hired in 2012-13, and is the first training specialist at Northeastern. She brings experience and knowledge from several organizations, and she also is charged with developing a University training strategy, so she also brings avenues for sustainability. The external consultant has served on design teams for many leadership development programs in industry and in academia including the ELATE (Executive Leadership in Academic Technology and Engineering) leadership program. She is an executive coach and consultant with an international clientele who range from multi-national corporations to universities. This broader design team provides more experience, is more diverse, and works together by challenging suggestions and refining processes.

The design of the second generation of ReDI responds to the evaluation of the first generation of ReDI (see Appendix II), and the specific feedback that faculty are prepared to spend time on an experiential project that benefits the research environment. Since there was no substantive input related to the nomination process, it remained unchanged. The Senior Vice Provost of Research and Graduate Studies requested deans to nominate faculty members. The nomination process created fourteen nominations with twelve invited to participate in ReDI Cohort II. This group represents 5 colleges, with 83\% associate professors, 17\% full professors; 7 women, and 5 men.

The second generation ReDI included a clear set of goals which were shared with participants at each meeting. Consistent with the original ReDI, the final goal is to develop a cohort of prepared and confident research leaders who wish to create research initiatives larger than their current scope of activities. These initiatives could include research consortia, research centers or large multi-institutional projects. The cohort includes a strong female representation. Specific goals for the second cohort are they will gain increased:

- Capacity to influence team dynamics and project outcomes through learning how to manage and leverage differences across working styles, approaches, backgrounds, and disciplines

- Strategies and methods within their toolkits for communication, project management, negotiation, and influencing people 
- Self-awareness of their leadership capabilities and ways to increase their impact in their roles as leaders

- Recognition and visibility by Northeastern leadership as proactive research leaders within and outside the institution

To accomplish the above stated goals, ReDI is implemented with four strategic activities.

I. Toolkit Workshops are designed to spur curiosity and learning on topics key to leading large initiatives or centers and to provide participants with new ways to assess situations resulting in tangible and actionable results. The goal of these workshops is not to create "experts" in the topic areas, rather to stimulate thinking about strategies around team building or communication, for example. The outcome objective of the workshops is to provide sufficient information so participants know where to go for more tactical information when needed.

II. Leadership Forums are platforms where experienced center directors and university leaders reflect and share experiences. Men and women center directors from both within and outside Northeastern reflect and share their personal experiences and the key ingredients they believe led to their success. The format encourages discussion and faculty members are encouraged to ask the leaders about their experience related to the workshop topics. One outcome from these leadership forums is the recognition of different leadership styles reinforced through discussions in the Toolkit Workshops.

III. Cohort Challenge is a team-based project where participants collaborate to identify and address current Northeastern issues that directly link to the institution's research enterprise. Beginning with suggested issues, each cohort further defines the challenge and then engages in the challenge during the academic year, leveraging information from the Toolkit Workshops and the Leadership Forums. During the 2013 - 2014 academic year the challenge topics are: 1) shared research facilities, 2) university-industry partnerships, and 3) development of competitive proposals. During the course of the team-work, a process coach works with the team to help them better understand and leverage their team dynamics. The cohort presents the project, recommendations, and solutions resulting from the challenge to Northeastern leadership at the end of the year closing session.

IV. Leadership Projects are where participants lead specific research initiatives tightly coupled to each participant's career goals. The leadership projects are stretch learning opportunities that enable each participant to achieve specific research goals. ReDI faculty members are encouraged to participate in Northeastern's research incentive programs to support the development of competitive proposals. Because each participant brings a different set of skills and experience, leadership or process coaches are available to participants to provide "just in time" feedback. These coaches enable the participant to navigate all aspects of the current project and to selfnavigate future projects. The result will be marked progress towards a professional 
goal within the context of new skills, increased self-awareness, and visibility with Northeastern leadership.

The schedule for ReDI Cohort II is included in Appendix III. Toolkit Workshops and Leadership Forums alternate each month. Participants engage in the Cohort Challenge together during the course of the academic year cumulating in a year-end meeting with university leadership. The Leadership Project is intended to be an activity that is close to a particular faculty member's career ambitions and is pursued when this aspiration is in line with a funding opportunity. This is not expected to be limited to the academic calendar. The Cohort Challenge and the Leadership Projects provide critical experiential opportunities that link to the leadership growth expected through ReDI.

In between each meeting, progress is debriefed with regard to tying lessons learned into the next session. The implementation team seeks to ensure that faculty are hooked, engaged, and rewarded through-out the year. These regular design team meetings ensure topical threads are pulled through across different speakers.

\section{Evaluation}

At the beginning of Cohort II ReDI course, we wanted to gather information on participants' goals, challenges, and expectations. A pre-survey asked them to respond online to five open ended questions. At the end of the course we will ask the same five questions and analyze them to determine if their language about leadership changes over the course of the ReDI experience. The questions asked in the pre-survey were:

1. Where are you called upon to exercise leadership in your current role?

2. What are your key (one to three) leadership strengths?

3. What is the biggest challenge or opportunity facing you right now? What makes this your biggest challenge or opportunity? Please provide as many specifics as possible. Please feel free to provide more than one if there are a few key challenges.

4. How do you hope participating in this program will help you address this challenge or opportunity?

5. What's the one thing you'd like most for the ReDI program administrators to know?

In summary, the pre-course survey indicated that all participants are already in roles that require them to exercise leadership in a variety of ways. They also seem clear in reporting their strengths, challenges, and needs from the program. Overall, they seem to love their jobs, enjoy in-depth research, and struggle to meet the demands of growth and expansion in the scope of their work and the challenges that come along with it. While they are excited to be selected for this program, their biggest concern at this time is balancing the demands of research, service, and administration.

We continue to ask for formative feedback after each Toolkit Workshop and each Leadership Forum. The feedback goes directly to the design team and to the presenters. In the first three Toolkit Workshops the participants were asked what was the best part of the workshop: 
"I loved the exercises and the differences in the perception of the goal between us. I also liked the discussion and tools of white space, perceptions and data."

[The best part of the workshop was] "giving a framework for understanding leadership styles. Talking about how to work on strengths not necessarily improve weaknesses."

"I found this workshop to be the most valuable one thus far. I didn't realize how "little" I knew about the detailed steps in moving a project from the conceptual stage to completed proposal. As a result, I learned the most from Ralf Birken's terrific presentation."

"The materials that were distributed were very valuable and have allowed me to follow up on each topic that was covered in the presentation. I found myself reading the material on the train home after having spent the entire afternoon going through it."

When asked about what they learned during the Leadership Forums, they reported:

"Her discussion made clear to me that gender is still very much an issue in leadership (which I already knew). I also learned that if successful, your initiatives might actually outgrow you."

"Don't be afraid to do things in which you feel out of your league. That is when you learn the most."

The evaluation plan for ReDI Cohort II includes the formative feedback mentioned above as well as an end of course online survey, tracking the participants' grant activity (including how many submit for Northeastern funded planning grants), and tracking how many move to administrative and large research leadership positions.

\section{Conclusion}

The Research Leadership Development Initiative (ReDI) is grounded in research and designed to align with both institutional culture and institutional research goals. The program design addresses institutional needs and will grow as Northeastern grows. As a result of two iterations of ReDI, we have learned the following: 1) workshop materials must be framed to use university applications, language, and examples; 2) faculty participants need to experience the program as a whole program, not a series of sub-components; 3 ) the design team gains strength from both internal and external members from operationally different administrative layers; and 4) faculty members need experiential opportunities to learn and apply new leadership skills. As we move forward, it is our intention to track individual member's accomplishments and interview them annually to determine the long-term value of the ReDI experience. The program will remain under the auspices of the Office of the Provost with the Senior Vice Provost for Research and Graduate Education and the Vice Provost for Academic Affairs most directly involved. 


\section{Bibliography}

1. HERS: Higher Education Resource Services. Retrieved November 1, 2012 from http://www.hersnet.org

2. ELAM: Executive Leadership in Academic Medicine. Retrieved November 1, 2012 from

https://www.drexelmed.edu/Home/OtherPrograms/ExecutiveLeadershipinAcademicMedicine.aspx

3. ELATE: Executive Leadership in Academic Technology and Engineering. Retrieved November 1, 2012 from http://www.drexel.edu/engineering/programs/special_opp/ELATE/

4. Madsen, S.R., Longman, K.A., \& Daniels, J.R. (2102). Women’s Leadership Development in Higher Education: Conclusion and Implications for HRD. Advances in Developing Human Resources, 14(1) 113-128.

5. Ely, R.J., Ibarra, H. \& Kolb, D. (2011). Taking Gender into Account: Theory and Design for Women’s Leadership Development Programs. [Special Issue]. Teaching Leadership - Taking Gender into Account: Theory and Design for Women's Leadership Development Programs, Vol. 10, (3) September. Academy of Management Learning \& Education.

6. Calas, M.B., \& Smircich, L. (2009). Feminist perspectives on gender in organizational research: What is and is yet to be. In D. Buchanan \& A. Bryman (Eds), Handbook of organizational research methods: 246-289. London: Sage Publications.

7. Ely, R.J., \& Meyerson, D.E. (2000). Theories of gender: A new approach to organizational analysis and change. Research in Organizational Behavior, 22: 103-153.

8. Kolb, D.M. \& McGinn, K. (2009). From gender and negotiation to gendered negotiation. Negotiation and Conflict Management Research, 2(1): 1-16.

9. Sturm, S. (2001). Second generation employment discrimination: A structural approach. Columbia Law Review, 101: $458-568$

10. Eagly, A.H. \& Carli, L.C. (2007). Through the labyrinth: The truth about how women become leaders. Boston, MA: Harvard Business School Press.

11. Parker, M. \& Welch, E.W. (2013). Professional networks, science ability, and gender determinants of three types of Leadership in Academic Science and Engineering. The Leadership Quarterly, 24, 332-348.

12. Gray, D.O. \& Rivers, D. (2012). Final Report: Social and Human Capital Impacts of the I/UCRC Program on Faculty Directors. Retrieved on November 1, 2012 from http://www.ncsu.edu/iucrc/PDFs/STHC_FinalReport.final.pdf 


\section{Appendix I}

\section{Agenda for ReDI Cohort I, fall 2012}

Foundations of Leadership

Instructor: Steven McGonagle, Professor of Practice in Engineering Leadership and Simon Pitts, Director, Gordon Engineering Leadership Program

Guest: Lisa Feldman-Barrett, Distinguished Professor Psychology

\section{Self - Assessment}

Instructor: Rose DiMarco, Senior Coop Coordinator Bouve College of Health Sciences Guest: Rich DeJordy, Assistant Professor, Management and Organizational Development

\section{Communication Strategies}

Instructor: Michael Woodnick, Professor of Communications Studies

\section{Launching and Running Large Projects}

Instructor: Katy Tucker, Professor, Health Sciences

Guest: Laura Lewis, Cabot Professor of Chemical Engineering

\section{Team Building Theory and Practice}

Instructor: Steven McGonagle, Professor of Practice in Engineering Leadership and Simon Pitts, Director, Gordon Engineering Leadership Program

Guest: Mel Bernstein, Senior Vice Provost for Research and Graduate Education

\section{Conflict Management Strategies}

Instructor: Steve Buchholz, Mastery Leadership Coach, Emergence

\section{Contracts and Budgeting}

Instructor: Jack McDevitt, Associate Dean for Research College of Social Sciences and Humanities and Debbie Grupp-Patrutz, Associate Provost Research and Administration Guest: Chip Storey, Assistant Dean of Research Bouvé College of Health Sciences

\section{Negotiation Skills}

Instructor: Ed Wertheim, Associate Professor \& Group Coordinator, Management and Organizational Development

Guest: Michael Silevitch, Professor of Electrical and Computer Engineering 


\section{Appendix II}

\section{Evaluation Summary ReDI Cohort I}

The program evaluation consisted of three components: 1) an online survey after each workshop, 2) an end of semester online survey, and 3) a participant round table discussion.

End of Workshop Online Survey

At the end of the fall semester (the workshop series), an online 17 item survey was administered with a mixture of ratings and short answers. Participants were also asked their opinion about future plans for ReDI. Eight of 14 (57\%) participants responded.

1. At the beginning of ReDI, the participants were asked why they chose to participate in the program. Their responses were then listed on the end of program survey and they were asked to what degree they found ReDI had satisfied each of their original reasons to participate. The participants rated each reason on a 5 point Likert scale from Did Not Satisfy (1) to Extremely Satisfied (5).

- Learning skills of an effective research leader (4.0)

- Learning how to manage budgets (4.0)

- Learning new communication strategies (3.5)

- Learning to inspire others (3.0)

2. We asked them rate each workshop on a 5 point Likert scale from Not at All Valuable

(1) to Extremely Valuable (5):

- Self-Assessment (MBTI was used) (3.7)

- Foundations of Leadership (3.5)

- Negotiation Skills (3.3)

- Communication Strategies (DISC was used) (3.2)

- Team Building Theory and Practice (3.0)

- Launching and Running Large Projects (2.7)

- Conflict Management Strategies (2.5)

- Contracts and Budgeting (2.2)

Participant comments included:

"The most useful were the workshops involving communication approaches, conflict resolution, etc. There were very real issues and helpful strategies. The ones involving self-assessment and negotiation skills were helpful in they allowed us to reflect on our skills and where we need to strengthen them."

"The sessions on communication styles and self-assessment (MBTI) were very good. In addition to theory, the presenters gave a lot of practical examples that were helpful."

"[Faculty presenter] was good because she has been through the process we are trying to follow." 
3. We asked them to what extent did participating in ReDI help them move toward their research goals and to explain how it helped. A sampling of their responses is below:

"I wanted to understand why we should bother with center grants. I have maintained 5-8 active grants at a time since I've been at Northeastern, and see value in diversification and the maintenance of a large cadre of collaborators research topics that would not necessarily be satisfied if I replaced them with a single large grant. The rationale given on the first day was not entirely satisfactory."

"I wanted to understand how one goes about getting organized to pursue a center grant, from concept to submission. I heard a little from [faculty presenter] that helped in this regard. The focus of the course seemed to be on general management strategies. That is, of course, very helpful, but does not directly address this issue.”

"The ReDI course had very ambitious goals, which I do not think were entirely met. However, I was generally satisfied with the course and learned about myself as a leader and some techniques for dealing with/ motivating others that are of different personality types. Given the amount of time I spent on it, I learned quite a bit. I am enjoying reading the negotiation book and other materials.”

4. We asked them what topic(s) they thought would be valuable to add to ReDI and to explain why.

“Possibly a session on 'effectiveness' would be good, including issues like time management, specific strategies for delegation, etc. More very specific suggestions for project management would also be useful."

“ORAF pre-award support for large grants.”

“More contact with other successful center directors.”

"Case studies with real center directors at Northeastern University and elsewhere. Invite directors of large centers at Northeastern and from other Boston area universities to discuss their thoughts, strategies and lessons learned. Invite senior faculty who have been or are center directors from across multiple disciplines."

5. We asked if there were any topics they thought should be discontinued and to explain their response(s). A sampling of their responses are below.

"I wouldn't remove any topics, I would just focus them more on academic examples and situations.” 
"Launching and Running Large Projects - instead of finding a couple of center/large project directors come and present a slide deck on their projects (i.e. what they are doing now), get a couple of them to come in, sit in front of the group, and talk without slides about how they got there, intellectually, funding-wise, and politics-wise, and insist on engagement of them with audience members."

6. We asked them to describe how they used something they had learned in the ReDI.

"The relationship I have with one of my students was very tense earlier in the fall, and the sessions on team building and the faculty speaker at the contract session prompted me to become much more reflective about the student's and my roles and responsibilities, as well as our difficult communications. My way of communicating with the student changed a bit, and the student has been less combative and more motivated since then. I was beginning to wonder if I could be an effective advisor to this student, and now I think this will be very productive."

"I considered the personality type of one of the other attendees and modified my way of interacting with him accordingly."

"Thinking of myself as a leader, or coach, rather than a manager, helps me day to day with my students and keeping a positive outlook."

7. We asked them if they wanted to continue in spring 2013, what information they wanted and what topics they were most interested.

Most requested sessions were:

Round Table discussion 5

Informal discussion with current center directors 5

Informal discussions with administrators 4

Book reviews 2 


\section{Appendix III}

\section{Agenda for ReDI Cohort 2 (2013-14)}

October 24

Research Leadership Development Initiative kick*-off, 1:30 - 5:30, 409

Dana Research Center

Stephen W. Director, Provost and Senior Vice President

Toolkit Workshop on "Leadership Framework"

Sabina Nawaz, Consultant

November $12 \quad$ Leadership Forum: 11:30 - 1:00, Frost Lounge

Fran Berman, Edward G. Hamilton Distinguished Professor in Computer

Science, Chair, Research Data Alliance/U.S., Director, Center for a Digital

Society, Rensselaer Polytechnic Institute

December $6 \quad$ Toolkit Workshop: 1:30 - 5:30, 431 Stearns

Mel Bernstein, Senior Vice Provost for Research and Graduate Education "Building and Leading Highly Productive Teams"

Steven McGonagle, Professor of Practice in Engineering Leadership and Steve Ruggieri, Executive Consultant

January $28 \quad$ Leadership Forum: 11:30 - 1:00, Frost Lounge

Barbara Shinn-Cunningham, Founding Director of the Center for Computational Neuroscience and Neural Technology (CompNet), Director and PI of the NSF-sponsored CELEST Science of Learning Center at Boston University

February 12 Toolkit Workshop: 2:30 - 6:30, Egan 440

"Project Management and Budgets"

Ralf Birken, Research Assistant Professor of Civil and Environmental Engineering

March 14 Leadership Forum: 11:30 --1:00, Alumni Center

Mansoor Amiji, Distinguished Professor and Department Chair of

Pharmaceutical Sciences and Co-Director, Nano-medicine Education and

Research Consortium

April 9

Toolkit Workshop: 2:30 - 6:30, Alumni Center

"Communication Across Cultures and through Smooth and Stormy

Waters"

Sabina Nawaz, Consultant

April 29

Leadership Forum: 11:30 - 1:00, Cabral Center

Geoffrey Trussell, Professor, Chair of the Department of Marine and Environmental Sciences, Director of the Marine Science Center 
May 6

Leadership Reflections \& Feedback: 1:30 - 3:30, Alumni Center Cohort Challenge Reports to Provost Leadership Team 